Journal of Clinical Investigation

Vol. 41, No. 11, 1962

\title{
THE MECHANISM OF THE INCREASED VENOUS PRESSURE WITH EXERCISE IN CONGESTIVE HEART FAILURE * $\dagger$
}

\author{
By J. EDWIN WOOD \\ (From the Department of Medicine and the Georgia Heart Association Laboratory for Cardio- \\ vascular Research, Medical College of Georgia, Augusta, Ga.)
}

(Submitted for publication, May 21, 1962 ; accepted July 26, 1962)

In 1930 Keefer observed that muscular exercise was of prime importance in precipitating the clinical manifestations of congestive heart failure in beriberi as well as other forms of heart disease (1). Further work since that time has not modified this opinion in the mind of the physician or the physiologist, but has raised questions as to the mechanism involved $(2,3)$.

In the present experiments, patients with overt congestive heart failure and patients who had recovered from congestive heart failure were studied with regard to their peripheral venomotor and venous pressure responses to mild exercise of the legs. The effect of sympathetic ganglioplegia upon the responses to exercise was investigated. The studies were repeated with circulatory arrest of the exercising legs.

These experiments indicate that the mechanism of the increase in venous pressure with exercise is an efferent sympatho-adrenal discharge with constriction of the peripheral veins. The level of exercise employed did not produce the venoconstriction in compensated patients.

\section{METHODS}

Patients with cardiac decompensation due to hypertension, aortic and mitral valvular disease, coronary artery disease, and advanced pulmonary disease were studied. Patients who had had congestive heart failure, but were compensated at the time of study served as control subjects. The criteria for the presence of congestive heart failure were roentgenographic and electrocardiographic evidence of heart chamber enlargement commensurate with the cardiac handicap. Sustained diastolic hypertension, murmurs indicative of aortic or mitral

* Submitted in honor of Chester S. Keefer, M.D., and the Golden Anniversary of the Evans Memorial Department of Clinical Research, Boston, Mass.

$\dagger$ Presented in part at the meeting of the American Society for Clinical Investigation, Atlantic City, New Jersey, May, 1959. These studies were supported by grants from the U. S. Public Health Service (H-4484 and $\mathrm{H}-4453$ ). valvular disfunction, electrocardiographic evidence of myocardial infarction, or X-ray and electrocardiographic evidence of cor pulmonale were the evidences of specific lesions. Further, peripheral edema or rales in the bases of the lungs were present in most cases. These signs disappeared with therapy for congestive heart failure. An acute loss of weight occurred in all cases after therapy. The increase in venous pressure with exercise, observed in these studies, also indicated the presence of congestive heart failure (Tables I and II). None had clinical evidence of tricuspid valve insufficiency.

All subjects were studied approximately one hour after the noon meal in a room where the temperature was kept constant at $72^{\circ} \mathrm{F}$. Studies were carried out with the patient in bed in a 30-degree, head up position. The patient was able to rest for a period of at least one hour before the experiment began. Venous pressure was measured with a saline manometer. Values obtained are reported in millimeters of $\mathrm{Hg}$ above the level of the right atrium (4). The patient exercised, without changing his posture, by alternately pressing his feet against a pedal device at a rate of one stroke of each leg per second. Approximately three pounds of pressure was required to depress each pedal. The stroke of the pedals was ten inches except during ischemia of the legs of patients with cardiac decompensation. In these patients the stroke was four inches and motion was confined to the ankle joint.

Distensibility of the peripheral veins was measured with a plethysmograph (5). The height of the column of water in the plethysmograph, above the level of the forearm, was sufficient to counterbalance the local venous pressure not only at rest but during exercise. Since a saline manometer was used to measure peripheral venous pressure in the opposite arm, it was possible to insure that the rise of venous pressure with exercise did not exceed the level of water in the plethysmograph. The accuracy of the measurement of venous volume with this method depends upon the presence of an initial, local, transmural, venous pressure that is constant at $1 \mathrm{~mm} \mathrm{Hg}$. With this constant starting point, the forearm was congested by raising pressure in the upper arm cuff by 5 $\mathrm{mm} \mathrm{Hg}$ increments, and the resultant forearm volume changes were recorded. The results of experiments carried out in this way could be plotted in terms of a pressure-volume curve before and during exercise (Figure 1). The volume of blood in the veins of the forearm, at the level of the right atrium, could be determined by plotting the venous pressure against the concomitantly observed venous pressure-volume curve (Figure 1). This 
TABLE I

Average forearm venous volume [30] and venous pressure, before and during exercise of legs, in subjects with congestive heart failure, before and during ganglionic blockade

\begin{tabular}{|c|c|c|c|c|c|c|c|c|c|}
\hline \multirow[b]{3}{*}{ Subject } & & \multicolumn{4}{|c|}{ Before ganglionic blockade } & \multicolumn{4}{|c|}{ During ganglionic blockade } \\
\hline & & \multicolumn{2}{|c|}{ Venous volume [30] } & \multicolumn{2}{|c|}{ Venous pressure } & \multicolumn{2}{|c|}{ Venous volume [30] } & \multicolumn{2}{|c|}{ Venous pressure } \\
\hline & & $\begin{array}{c}\text { Pre- } \\
\text { exercise }\end{array}$ & Exercise & $\begin{array}{c}\text { Pre- } \\
\text { exercise }\end{array}$ & Exercise & $\begin{array}{c}\text { Pre- } \\
\text { exercise }\end{array}$ & Exercise & $\begin{array}{c}\text { Pre- } \\
\text { exercise }\end{array}$ & Exercise \\
\hline & & \multicolumn{2}{|c|}{$m l / 100 m l$} & \multicolumn{2}{|c|}{$m m \mathrm{Hg}$} & \multicolumn{2}{|c|}{$m l / 100 m l$} & \multicolumn{2}{|c|}{$m m \mathrm{Hg}$} \\
\hline 1 & & 2.5 & 1.5 & 19 & 25 & $2.3^{1.1}$ & 2.3 & 19 & 20 \\
\hline 2 & & 3.1 & 1.0 & 6 & 18 & 3.3 & $\begin{array}{l}2.0 \\
3.3\end{array}$ & 5 & 7 \\
\hline $\begin{array}{l}2 \\
3\end{array}$ & & $\begin{array}{l}0.1 \\
2.7\end{array}$ & $\begin{array}{l}1.1 \\
1.7\end{array}$ & 18 & $\begin{array}{l}10 \\
27\end{array}$ & $\begin{array}{l}0.0 \\
2.9\end{array}$ & $\begin{array}{l}0.0 \\
2.9\end{array}$ & 15 & 17 \\
\hline 4 & & 3.6 & 1.7 & 13 & 19 & 3.9 & 3.9 & 11 & 11 \\
\hline 5 & & 2.2 & 1.2 & 22 & 29 & 3.1 & 3.2 & 19 & 22 \\
\hline 6 & & 2.9 & 1.8 & 10 & 16 & 2.6 & 2.9 & 9 & 10 \\
\hline 7 & & 1.7 & 0.8 & 24 & 26 & 1.9 & 1.8 & 16 & 17 \\
\hline 8 & & 2.3 & 1.5 & 24 & 30 & 2.4 & 2.4 & 22 & 23 \\
\hline 9 & & 1.9 & 0.8 & 19 & 29 & 2.6 & 2.0 & 17 & 18 \\
\hline 10 & & 2.4 & 1.8 & 9 & 20 & 2.9 & 2.6 & 7 & 9 \\
\hline 11 & & 2.3 & 1.1 & 9 & 27 & 2.3 & 2.5 & 8 & 11 \\
\hline \multirow[t]{3}{*}{12} & & 3.3 & 0.6 & 13 & 25 & 3.8 & 3.7 & 10 & 11 \\
\hline & Mean & 2.6 & 1.3 & 16 & 24 & 2.8 & 2.8 & 13 & 15 \\
\hline & SD & 0.57 & 0.42 & 6.3 & 4.8 & 0.61 & 0.65 & 5.5 & 5.4 \\
\hline
\end{tabular}

value is referred to as the natural, local venous volume. The volume of the segment of the forearm within the plethysmograph was measured at the conclusion of each experiment by displacement. All values for venous volume were calculated in terms of milliliters per $100 \mathrm{ml}$ forearm tissue.

It has been previously deduced that prior to congestion the volume of blood within the veins of the extremity is constant. The transmural pressure of the veins is also constant. When the veins are congested to a higher transmural pressure (e.g., $30 \mathrm{~mm} \mathrm{Hg}$ ), a relatively smaller increase in volume occurs in the presence of a venoconstrictor stimulus. All observations are reported in terms of the volume change of $100 \mathrm{ml}$ of forearm tissue in response to a rise of effective venous pressure of $30 \mathrm{~mm} \mathrm{Hg}$ and are referred to as venous volume [30] (Figure 1). Thus, a relatively low value of venous volume [30] indicates peripheral venoconstriction (6).
A venous pressure-volume curve and a peripheral venous pressure were obtained simultaneously on three successive occasions during a period of approximately twenty minutes. The averages of the values observed are reported. The patient then exercised for a period of three to five minutes until he had reached a reasonably steady state, as evidenced by consistent readings of the repeatedly measured venous pressure. A venous pressurevolume curve and venous pressure were then obtained during exercise. Ganglionic blockade was induced with intravenous pentolinium tartrate 1 ( 2 to $6 \mathrm{mg}$ ). The dose was adjusted to the amount that had a minimal (less than $10 \mathrm{~mm} \mathrm{Hg}$ ) effect in reducing diastolic blood pressure. Then the studies of venous distensibility and venous pressure responses to exercise were repeated.

Comparable studies of the effect that exercise of the

1 Ansolysen, Wyeth.

TABLE II

Average forearm venous volume [30] and venous pressure, before and during exercise of legs with arterial occlusion, in subjects with congestive heart failure, before and during ganglionic blockade

\begin{tabular}{|c|c|c|c|c|c|c|c|c|c|}
\hline \multirow[b]{3}{*}{ Subject } & & \multicolumn{4}{|c|}{ Before ganglionic blockade } & \multicolumn{4}{|c|}{ During ganglionic blockade } \\
\hline & & \multicolumn{2}{|c|}{ Venous volume [30] } & \multicolumn{2}{|c|}{ Venous pressure } & \multicolumn{2}{|c|}{ Venous volume $[30]$} & \multicolumn{2}{|c|}{ Venous pressure } \\
\hline & & $\begin{array}{c}\text { Pre- } \\
\text { exercise }\end{array}$ & Exercise & $\begin{array}{c}\text { Pre- } \\
\text { exercise }\end{array}$ & Exercise & $\begin{array}{c}\text { Pre- } \\
\text { exercise }\end{array}$ & Exercise & $\begin{array}{c}\text { Pre- } \\
\text { exercise }\end{array}$ & Exercise \\
\hline \multirow[t]{2}{*}{$\begin{array}{l}1 \\
2 \\
3 \\
4 \\
5 \\
6\end{array}$} & & $\begin{array}{l}2.5 \\
3.2 \\
2.8 \\
3.8 \\
1.9 \\
3.2\end{array}$ & $\begin{array}{l}1.3 \\
1.1 \\
1.8 \\
2.4 \\
1.1 \\
1.9\end{array}$ & $\begin{array}{r}18 \\
6 \\
19 \\
11 \\
24 \\
10\end{array}$ & $\begin{array}{l}26 \\
18 \\
24 \\
20 \\
30 \\
16\end{array}$ & $\begin{array}{l}2.5 \\
3.3 \\
2.8 \\
3.0 \\
3.2 \\
2.7\end{array}$ & $\begin{array}{l}2.3 \\
3.2 \\
2.8 \\
3.9 \\
3.0 \\
2.9\end{array}$ & $\begin{array}{r}19 \\
6 \\
16 \\
9 \\
20 \\
9\end{array}$ & $\begin{array}{r}20 \\
6 \\
15 \\
10 \\
23 \\
10\end{array}$ \\
\hline & $\begin{array}{l}\text { Mean } \\
\text { SD }\end{array}$ & $\begin{array}{l}2.9 \\
0.66\end{array}$ & $\begin{array}{l}1.6 \\
0.53\end{array}$ & $\begin{array}{l}15 \\
6.7\end{array}$ & $\begin{array}{r}22 \\
5.3\end{array}$ & $\begin{array}{l}2.9 \\
0.32\end{array}$ & $\begin{array}{l}3.0 \\
0.53\end{array}$ & $\begin{array}{c}13 \\
5.9\end{array}$ & $\begin{array}{r}14 \\
6.5\end{array}$ \\
\hline
\end{tabular}




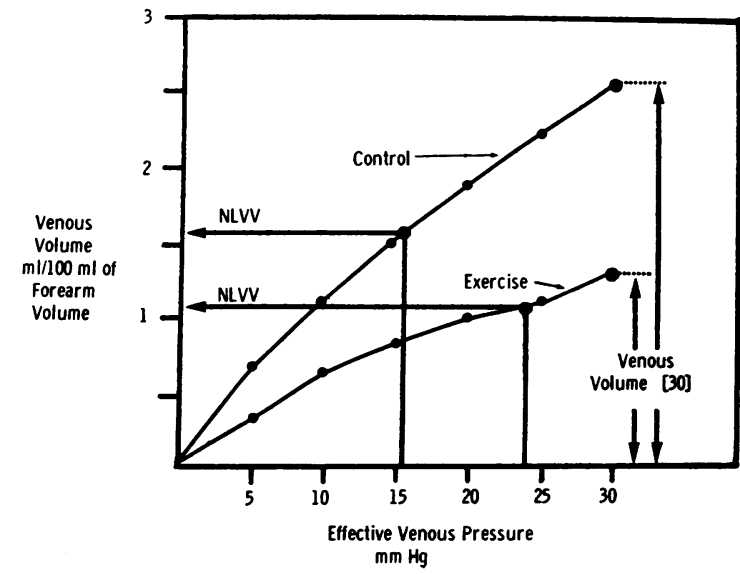

Fig. 1. Average, venous, PRessure-volume curves OF 12 PATIENTS WITH CONGESTIVE HEART FAILURE, WITHOUT GANGLIONIC BLOCKADE, BEFORE AND DURING EXERCISE. Concomitantly measured, peripheral, venous pressures utilized to deduce average, natural, local venous volume (NLVV) in each case.

lower extremity had upon forearm venous distensibility and venous pressure were carried out during circulatory arrest of the legs. Inflation of two cuffs on opposite sides of each upper thigh to suprasystolic pressure and consequent obliteration of pedal pulses insured that virtually all of the exercising muscles were temporarily excluded from the general circulation. Previous observations indicate that this procedure does interrupt the circulation as attested by the absence of volume increase of the leg during occlusion and by the reactive hyperemia that follows release of the cuffs (7). The cuffs were held in position by gauze and tape. No discomfort occurred with inflation. The degree of exercise used was not painful.

\section{RESULTS}

The effect of exercise upon venous volume [30] and upon peripheral venous pressure was measured in 12 patients with cardiac decompensation with and without ganglionic blockade (Table I). Prior to autonomic blockade the average venous volume [30] was significantly reduced during exercise, $\mathrm{p}<.01$. The average venous pressure, referred to the level of the right atrium, rose $8 \mathrm{~mm} \mathrm{Hg}$ during exercise in these experiments, $\mathrm{p}<.01$.

After pentolinium, venous volume [30] did not change significantly with exercise, $p>.5$. Likewise, the venous pressure in these experiments with ganglionic blockade did not rise significantly, p >.5. Eight patients showed a fall of $2 \mathrm{~mm} \mathrm{Hg}$ or less in resting venous pressure after pentolinium.
TABLE III

Average forearm venous volume [30] and venous pressure, before and during exercise of legs, in compensated subjects who had had congestive heart failure

\begin{tabular}{|c|c|c|c|c|}
\hline \multirow[b]{2}{*}{ Subject } & \multicolumn{2}{|c|}{ Venous volume $[30]$} & \multicolumn{2}{|c|}{ Venous pressure } \\
\hline & $\begin{array}{c}\text { Pre- } \\
\text { exercise }\end{array}$ & Exercise & $\begin{array}{c}\text { Pre- } \\
\text { exercise }\end{array}$ & Exercise \\
\hline 13 & 3.2 & 2.9 & 8 & 8 \\
\hline 14 & 3.9 & 4.1 & 14 & 15 \\
\hline 15 & 3.9 & 4.0 & 15 & 14 \\
\hline 16 & 4.0 & 4.2 & 7 & 7 \\
\hline 17 & 3.9 & 3.6 & 7 & 6 \\
\hline 18 & 3.6 & 3.7 & 14 & 15 \\
\hline 19 & 1.8 & 2.8 & 3 & 3 \\
\hline 20 & 3.4 & 2.9 & 11 & 11 \\
\hline 21 & 1.6 & 1.7 & 14 & 13 \\
\hline 22 & 3.9 & 4.0 & 9 & 8 \\
\hline 23 & 2.8 & 2.5 & 8 & 9 \\
\hline 24 & 4.1 & 4.2 & 14 & 16 \\
\hline Mean & 3.3 & 3.4 & 10 & 10 \\
\hline SD & 0.85 & 0.82 & 3.9 & 4.2 \\
\hline
\end{tabular}

The average, natural, local venous volume was $1.6 \mathrm{ml}$ at rest and $1.1 \mathrm{ml}$ with exercise, $\mathrm{p}<.01$ (Figure 1). The exercise induced mild dyspnea in all of the patients. Eight of the patients said that the dyspnea of exercise was less intense after pentolinium.

These studies of venous distensibility and venous pressure were performed in six of the patients with congestive heart failure and in conjunction with circulatory arrest of the mildly exercising lower limbs (Table II). The average venous volume [30] fell significantly while the patient exercised, $\mathrm{p}<.01$. The average venous pressure in these experiments rose $7 \mathrm{~mm} \mathrm{Hg}$ during exercise, $p<.02$. Ganglionic blockade was induced as before, and the average venous volume [30] did not change significantly during exercise,

TABLE IV

Average forearm venous volume [30] and venous pressure, before and during exercise of legs with arterial occlusion, in compensated subjects who had had congestive heart failure

\begin{tabular}{|c|c|c|c|c|}
\hline \multirow[b]{2}{*}{ Subject } & \multicolumn{2}{|c|}{ Venous volume $[30]$} & \multicolumn{2}{|c|}{ Venous pressure } \\
\hline & $\begin{array}{c}\text { Pre- } \\
\text { exercise }\end{array}$ & Exercise & $\begin{array}{c}\text { Pre- } \\
\text { exercise }\end{array}$ & Exercise \\
\hline 13 & 3.1 & 2.5 & 8 & 8 \\
\hline 14 & 3.8 & 3.7 & 14 & 15 \\
\hline 15 & 3.9 & 3.9 & 13 & 14 \\
\hline 16 & 4.0 & 4.0 & 7 & 8 \\
\hline 17 & 3.9 & 3.8 & 6 & 5 \\
\hline \multirow{3}{*}{$\begin{array}{l}\text { Mean } \\
\text { SD }\end{array}$} & 3.7 & 3.7 & 15 & 16 \\
\hline & 3.7 & 3.6 & 11 & 11 \\
\hline & 0.35 & 0.57 & 3.9 & 4.6 \\
\hline
\end{tabular}


$\mathrm{p}>$.5. Average venous pressures showed virtually no change.

Hospitalized patients were studied who were compensated, but who had had congestive heart failure. Venous volume [30] and venous pressure did not change significantly during exercise with or without arterial occlusion of the legs (Tables III and IV).

\section{DISCUSSION}

Starr pointed out in a personal communication to Harrison that the rise of venous pressure in congestive heart failure could not be accounted for without the proviso that some new energy be added to the venous system (3). The results of the present experiments support his prediction that acute constriction of the peripheral veins does in fact contribute the energy that results in the rise of pressure. In exercise the venous pressure rose concomitantly with constriction of the peripheral veins. When constriction of the veins was prevented by interruption of autonomic nerve impulses, the rise in venous pressure failed to occur. A fall in resting venous pressure, with ganglionic blockade, was not an essential accompaniment of the prevention of venous pressure rise with exercise. Thus, correction of functional tricuspid insufficiency by reduction of central venous pressure does not appear to be the mechanism involved (8). It has been suggested that the rise of venous pressure might be due to the increased flow of blood into the venous system from the exercising muscles, in combination with a reduced ability of the heart to remove this blood from the veins (9). The ultimate source of blood that would serve this mechanism in a closed circulation is obscure. Circulatory arrest of the legs did not prevent the rise of venous pressure; hence venous return from the exercising muscles seemed unrelated to this response of venous pressure. Although inefficient removal of excess blood from the veins by the heart does not appear likely to account for the rise in pressure, the reduction of the volume of blood in the peripheral veins with exercise apparently does result in a high central blood volume (10).

An increase of venous pressure of the order of magnitude observed in heart failure does not occur in normal subjects during peripheral venoconstriction (11). The increased blood volume in congestive heart failure in combination with the greater than normal resting venous tone (12) may combine to accentuate the effect of the further venoconstriction of exercise upon venous pressure.

Patients who were compensated showed no venoconstrictor response to the level of exercise utilized, and severe exercise of normal individuals (5) does not cause venoconstriction of the degree observed in the decompensated patients. This indicates that the responsiveness of this neuroeffector system is increased in congestive heart failure. Since venoconstriction with exercise does occur in normal individuals, the response may not be viewed as an abnormal reflex.

\section{SUMMARY AND CONCLUSIONS}

The peripheral venomotor and venous pressure responses to exercise of patients with congestive heart failure were studied. Venous distensibility of the forearm was measured with a plethysmograph during exercise of the legs. Constriction of the veins and a concomitant rise of venous pressure occurred with exercise in these patients. The responses to exercise were interrupted by a sympathetic ganglioplegic agent. Forearm venoconstriction occurred despite arterial occlusion of the exercising legs. The venoconstrictor response to the same exercise was not observed in compensated patients.

These experiments lead to the hypothesis that in congestive heart failure excessive venous pressure during exertion occurs primarily as a result of constriction of the veins. This constriction of veins is mediated by a sympatho-adrenal discharge. These results are opposed to the concept that excessive flow of blood into the venous system with inadequate removal of this blood by the handicapped heart results in elevated blood pressure within the veins.

\section{REFERENCES}

1. Keefer, C. S. The beriberi heart. Arch. intern. Med. 1930, 45, 1.

2. Landis, E. M., Brown, E., Fauteux, M., and Wise, C. Central venous pressure in relation to cardiac "competence," blood volume and exercise. J. clin. Invest. 1946, 25, 237.

3. Harrison, T. R. Failure of the Circulation, 2nd ed. Baltimore, The Williams and Wilkins Co., 1939.

4. Winsor, T., and Burch, G. E. The phlebostatic axis and phlebostatic level, reference levels for venous 
pressure measurements in man. Proc. Soc. exp. Biol. (N. Y.) 1945, 58, 165.

5. Wood, J. E., and Bass, D. E. Responses of the veins and arterioles of the forearm to walking during acclimatization to heat in man. J. clin. Invest. 1960, 39, 825.

6. Wood, J. E., and Eckstein, J. W. A tandem forearm plethysmograph for study of acute responses of the peripheral veins of man: the effect of environmental and local temperature change, and the effect of pooling blood in the extremities. J. clin. Invest. 1958, 37, 41.

7. Litter, J., and Wood, J. E. The volume and distribution of blood in the human leg measured in vivo. I. The effects of graded external pressure. J. clin. Invest. 1954, 33, 798.
8. McMichael, J., and Shillingford, J. P. The role of valvular incompetence in heart failure. Brit. med. J. 1957, 1, 537.

9. Friedberg, C. K. Diseases of the heart, 2nd ed. Philadelphia and London, W. B. Saunders Co., 1956, p. 166.

10. Braunwald, E., and Kelly, E. R. The effects of exercise on central blood volume in man. J. clin. Invest. 1960, 39, 413.

11. Eckstein, J. W., and Hamilton, W. K. The pressure-volume responses of human forearm veins during epinephrine and norephinephrine infusions. J. clin. Invest. 1957, 36, 1663.

12. Wood, J. E., Litter, J., and Wilkins, R. W. Peripheral venoconstriction in human congestive heart failure. Circulation 1956, 13, 524. 